\title{
Deep Learning Technology Based on Intelligent Teaching in Social Psychology Courses
}

\author{
https://doi.org/10.3991/ijet.v16i24.27255 \\ Dan Li \\ Yunnan Vocational Institute of Energy Technology, Qujing, China \\ yjyxiongmao@126.com
}

\begin{abstract}
Social psychology is a comprehensive course which is an interdisciplinary of sociology and psychology. Most colleges and universities have currently taken social psychology as a general course to popularize psychological knowledge to students, which has great significance to cultivating their quality. Previous teaching did not combine this course with social needs, the optimization of students' psychological needs and enhancement of their abilities to solve problems, on the contrary, pure theoretical interpretation was the focus, resulting in students' lacking of proactivity. Therefore, a new teaching mode for improvement is urgent. Based on deep learning theory and comprehensively taking teaching environment, teaching resources and technical strategy support into consideration, and intelligence as the core, the paper has designed an intelligent teaching mode including intelligent preview, intelligent classroom, intelligent promotion and intelligent evaluation. Meanwhile, combined with courses of social psychology, video, audio and text teaching resources and multimedia courseware, multimedia resources were integrated, and problem discussion-based collaborative learning was adopted for teaching. To accurately evaluate the teaching effect under the intelligent teaching environment, guided by the appeal of intelligent teaching and based on analysis of accurate teaching objectives, the paper has established an accurate teaching evaluation index system, aiming at providing an idea for "How to evaluate the effect of accurate teaching in the intelligent teaching environment". At last, the paper has applied the new teaching mode into the practice of social psychology, finding that the new mode can stimulate students' proactivity, improve their performance, which is worth promotion.
\end{abstract}

Keywords - intelligent classroom, accurate teaching evaluation, deep learning, social psychology

\section{$1 \quad$ Introduction}

Being a public elective course for all college students and different from general social science courses, Social Psychology is a subject which is closely related to the physical and mental health of college students [1]. Social psychology is closely related to individual's social behavior, thus, it can not only perfect students' psychological knowledge system, but also provide multi-aspect theoretical and practical guidance for their interpersonal skills, life skills, etc., becoming an important way to optimize their 
psychological quality. Social psychology equally focuses on theory and practice, and diversified teaching is beneficial to the teaching objectives. From the reality, however, there are still many problems of the teaching of social psychology, such as the single teaching means, imperfect evaluation system, outdated teaching concept, etc., seriously impacting the teaching effect [2]. Meanwhile, with the emergence of big data on the Internet and the outbreak of Covid-19, colleges and universities, in order to not negatively affect the study, have advocated teachers to use various on-line platforms to carry out personalized on-line teaching for students. With no doubt, social psychology is not an exception. However, some teachers do not have enough recognition of the new teaching mode that personalized teaching cannot be fully implemented, and the data analysis of students' interaction is not deep enough. And the lacking of interaction with students in the teaching process results in insufficient data information, thereby cannot embody the superiority of interactive teaching. In traditional mode of teaching, knowledge is transferred from teachers to students, who passively accept. Teachers divide students into different levels according to their scores, which lacks interaction. The greatest characteristic of collaborative learning based on deep learning is the equality between teachers and students, as well as the contextualization, life-orientation and collaboration to give play to students' proactivity and creativity [3]. Based on the theory of deep learning, the study intends to establish an intelligent teaching mode including intelligent preview, intelligent classroom, intelligent promotion and intelligent evaluation.

\section{$2 \quad$ State of the art}

Social psychology plays an important role in cultivating students' good psychological quality and improving their attitude of practice. Therefore, it is crucial in college curriculum and the cultivation of students' quality. Some scholars have currently reformed the teaching of social psychology and obtained positive outcomes. Innes et al. [4] proposed that in teaching social psychology, the process of identifying a particular theorist can lead to an enhanced understanding of the theories associated with that individual. They guided students to critically evaluate and rank the contributions of several important figures in the history of social psychology. The results showed that the most popular triads included various combinations of Festinger, Asch and Milgram. This teaching method was also highly recognized by students and teachers. Based on social psychology, Koca-Atabey [5] revisited the Stanford Prison Experiment (SPE) from the perspective of disability studies. And he reckoned that the SPE was an issue that inevitably came to light while teaching Social Psychology and how it contributed to a different course titled Psychological, Social and Cultural Aspects of Disabilities. The report has summarized SPE as A ground-breaking study in the field of social psychology teaching. Bramesfeld et al. [6] applied the game approach to social psychology courses, who presented the results of two studies that evaluated an experiential intersectionality awareness activity, C'est La Vie: The Game of Social Life. Across both studies, playing C'est La Vie was associated with an expanded awareness of privilege and structural inequality. Kim et al. [7] integrated self-determination theory into the 
teaching of social psychology. They aimed to gain in-depth understanding of typical manifestations of the positive (autonomy support, structure, involvement) and negative (autonomy thwart, chaos, disaffection or reject) dimensions of need supportive teaching by relating these to educational approaches of schools.

With the development of teaching methods, teaching method in psychology field in China is also being studied and explored, and educators are also gradually improving traditional teaching concepts, methods and relevant teaching measures. Starting from social interaction, $\mathrm{Li}$ et al. [8] analyzed the new characteristics of individual personality in social media interaction represented by Weibo, such as the spirit of giving and sharing, cooperation, the increase of altruistic behaviours and playing the role of others, and they designed a new teaching method of social psychology which increased students' interest in learning. Pei et al. [9] applied case teaching and situation simulation to nursing psychology teaching and compared the effect with traditional teaching mode. They found that these two teaching modes could be combined in nursing psychology teaching, which improved students' understanding of knowledge, and effectively promoted students to analyse and solve problems as well as improved their professional abilities. The teaching experiment results were satisfactory. Kou et al. [10] believed that the teaching of social psychology could be based on students' needs and learning patterns. They found that students had strong needs in application and emotion. On this basis, their team had adjusted and innovated in teaching design combined with learning pattern, focused on extracurricular reading, and established a learning \& socializing-integrated platform.

With the emergence of various research fields of educational technology, deep learning has gradually attracted the attention of many scholars, who have made deep exploration in the discussion of deep learning in teaching practice [11]. Zhang et al. [12] carried out an experiment of teaching environment intelligent classroom for teachers and students, analyzed learners' experience through questionnaires, and verified whether the designed evaluation system was able to improve the teaching system and promote learning. Researchers et al. [13-15] put forward that with the development of information technology, technology and methods shall be integrated to form intelligent classroom to make the intelligent classroom come into being and be sustainably developed. Wang et al. [16] applied the immersive learning activity to the simulation experiment of biology, in which techniques were used for full display and enhancing the sense of experience. Through the teaching cooperation, students participated in the course formed a complete system of knowledge of biology. However, from the current teaching of social psychology, it has not been given a full play as a course to improve the psychological quality of college students. Meanwhile, there have been few reports on how to carry out teaching research on deep learning in psychology. In view of this, a new teaching mode is in urgent needs to break the current teaching mode. Based on Internet deep learning, the study has taken intelligent teaching as the main subject to establish a new intelligent teaching mode combined with the characteristics of social psychology courses. Meanwhile, issue-discussion collaborative learning method has been used for the interaction of teachers and students. It is expected that this teaching mode can provide reference for other psychology teaching. 


\section{The integration of intelligent classroom based on deep learning into the teaching of social psychology}

\subsection{The application of intelligent classroom in teaching}

Intelligent classroom is a typical materialization of intelligent learning environment, which is a high-end form of multimedia and network classroom. It is a novel classroom established by Internet of Things technology, cloud computing technology and intelligent technology, which includes tangible physical space and intangible digital space, realizing situational awareness and environmental management through various intelligent equipment for the presentation of teaching content, the facilitation of the acquisition of learning resources and the promotion in classroom interaction. Intelligent classroom aims at providing humanized and intelligent interactive space for teaching, improving the relationship between people and the learning environment through the combination of physical space and digital space, and local and remote learning, enabling people and the environment to interact with each other in the learning space and promoting personalized learning, open learning and ubiquitous learning.

Teachers and students are the most fundamental elements in class activities. The mutual interaction of them can make students more proactive and become the main body to stimulate their interest in learning. Figure 1 has shown that mobile rostrum, desks and chairs and other facilities have changed the main body of the class in the intelligent classroom. The interaction has changed from teacher to class to teacher to students, students to students, teacher to groups, students to groups and other forms. Students' learning appeal has become the main body in the interaction, and their characters have also been transformed in various forms of learning such as theoretic lecturing, case discussion, etc., showing a learner-centred teaching concept and creating multi-dimensional activities. 


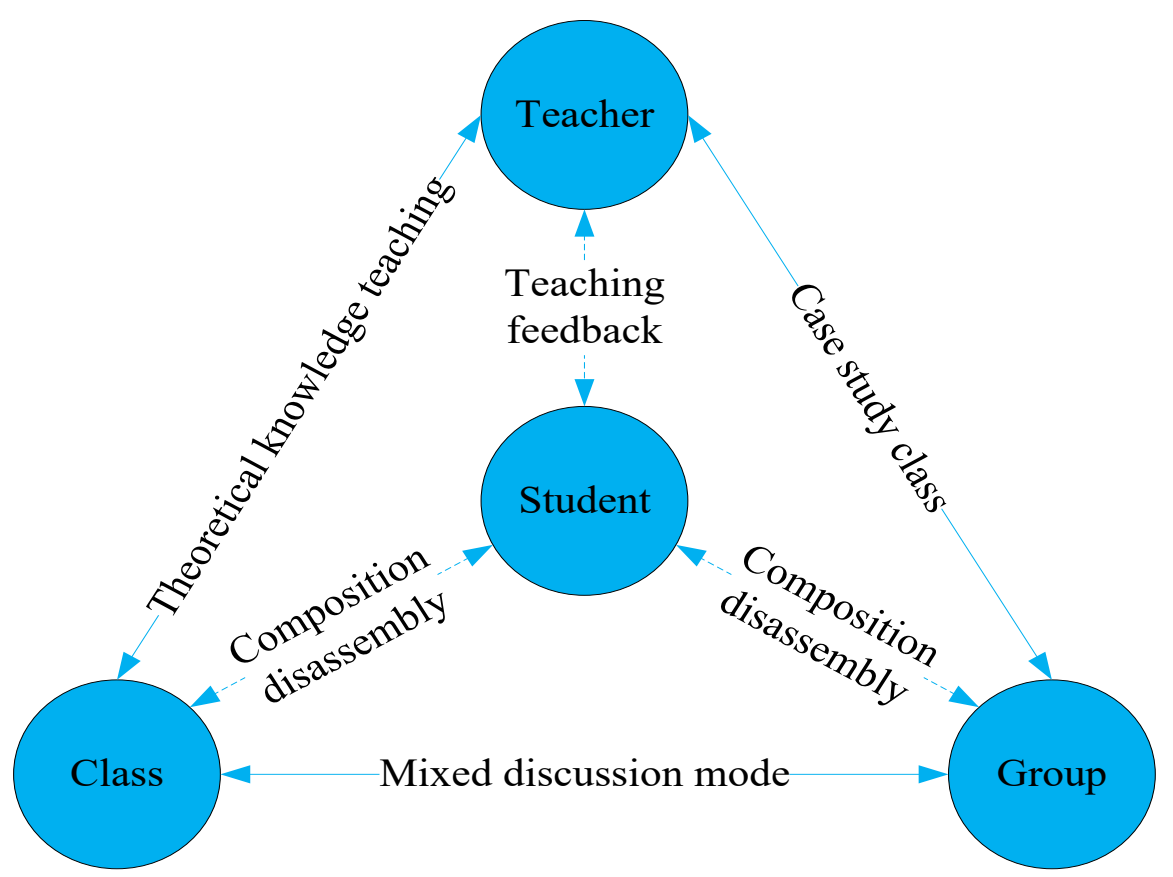

Fig. 1. Composition diagram of intelligent interaction mode

\subsection{Establishment of teaching effect evaluation of intelligent classroom based on deep learning}

The key point of analytic hierarchy process is hierarchy structure. In this study, the hierarchy of the accurate teaching evaluation index system in the intelligent teaching environment was divided into three layers. Among them, the target layer is the evaluation of the goal to achieve, including "knowledge level", "process level" and "emotional level" and other first-level evaluation indicators; Criterion layer is the middle layer, including "knowledge acquisition", "academic performance" and other secondary indicators; The solution layer is a specific solution to the problem, including three-level indicators such as "knowledge acquisition" and "skill improvement", as shown in Figure 2. 


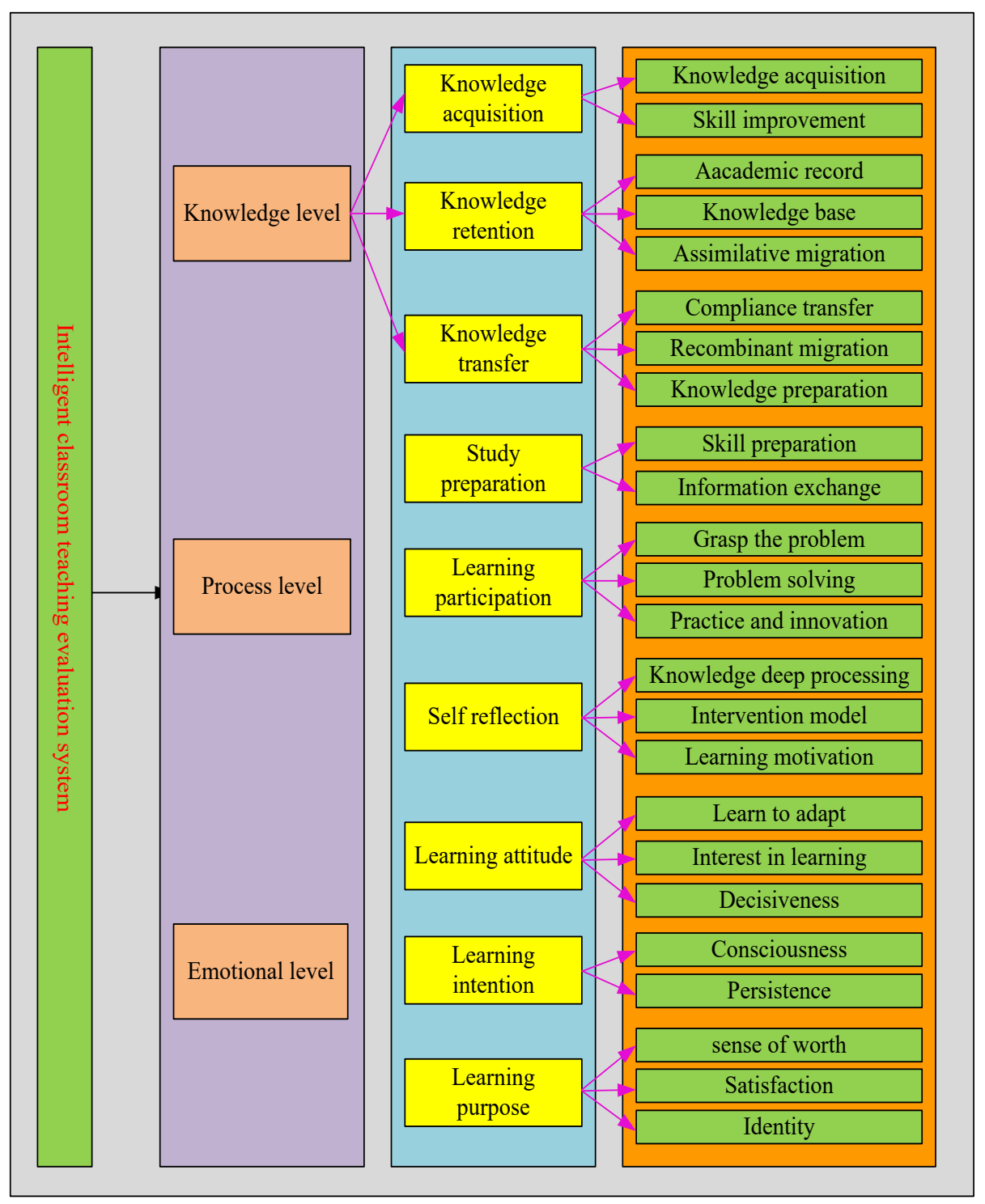

Fig. 2. Diagram of the model of teaching evaluation system of deep learning-based intelligent classroom

Hierarchical single sorting refers to the calculation of the weight of importance order of factors related to a factor at the last level according to the judgment matrix.

Hierarchical single sorting can be concluded as the problem of calculating the eigenvalues and eigenvectors of the judgment matrix, which, for the judgment matrix $B$, the eigenvalues and eigenvectors satisfying the following equation has been calculated.

$$
B W=\lambda \max W
$$


Where $\lambda \max$ was the maximum eigenvalue of $\mathrm{B} ; \mathrm{W}$ was the normalized eigenvector corresponding to $\lambda \max$; The component ${ }^{w_{i}}$ of $\mathrm{W}$ was the weight of the single sorting of the corresponding factor.

The second step of analytic hierarchy process was to establish the judgment matrix and determine the weight of each element by comparing their importance. By means of questionnaire and through consultation of experts, the research team scored the importance of the evaluation elements in the hierarchy. According to the relative importance scale proposed by T L Satty, the score ranged from 1 to 9, among which 1, 3, 5,7 , and 9 respectively represented equally important, relatively important, important, very important, and extremely important. The other four even numbers between these odd numbers represented the middle values of adjacent importance degree. Restricted by the length of the paper, the study has taken experts' evaluation data on first-level indicators as an example to briefly explain the calculations process of weights in the evaluation indicator system, as shown in Table 1.

Table 1. Experts' scoring statistics on the importance of first-level indicators

\begin{tabular}{|l|c|c|c|}
\hline \multicolumn{1}{|c|}{ First-level indicators } & Knowledge level & Process level & Emotion level \\
\hline Knowledge level & 1 & $1 / 3$ & 2 \\
\hline Process level & 3 & 1 & 5 \\
\hline Emotion level & $1 / 2$ & $1 / 5$ & 1 \\
\hline
\end{tabular}

Firstly, matrix A was constructed according to the importance scores of the firstlevel indicators given by the experts.

Then, matrix A was normalized. The process and results of the first column of the normalization was shown below:

$$
\begin{gathered}
1 /(1+3+1 / 2)=0.22 \\
3 /(1+3+1 / 2)=0.67 \\
1 / 2 /(1+3+1 / 2)=0.11
\end{gathered}
$$

The second and third column were normalized in the same way, and matrix B was constructed using the results of the normalization.

$$
B=\left|\begin{array}{lll}
0.22 & 0.22 & 0.2 \\
0.67 & 0.65 & 0.63 \\
0.11 & 0.13 & 0.12
\end{array}\right|
$$

Again, by adding up each row of matrix B, matrix $\mathrm{C}$ with one column was obtained.

$$
C=\left|\begin{array}{l}
0.69 \\
1.95 \\
0.36
\end{array}\right|
$$


At last, matrix $\mathrm{C}$ was normalized to obtain the final weights of each indicator, namely,

$$
\begin{aligned}
& 0.69 /(0.69+1.95+0.36)=0.23 \\
& 1.95 /(0.69+1.95+0.36)=0.65 \\
& 0.36 /(0.69+1.95+0.36)=0.12
\end{aligned}
$$

Therefore, the weight of each first-level indicator calculated by the experts was as follows: the weight of knowledge level was 0.23 , the weight of process level was 0.65 , and the weight of emotion level was 0.12 .

By carrying out the consistency analysis of judgment matrix A, the coordination of weight coefficient generation was determined. Firstly, the maximum eigenvalue $\lambda \max$ corresponding to the judgment matrix was calculated by the following equation:

$$
\lambda \max =\sum_{i=1}^{n} \frac{(A W)_{i}}{n W_{i}}
$$

where (AW) I was the ith dimension of the vector matrix, which was calculated as $\lambda \max =3.004$.

Then, the first-level indicator CI of the judgment matrix was calculated as

$$
C I=\frac{\lambda \max -n}{(n-1)}
$$

the result was $\mathrm{CI}=0.002$.

Finally, the corresponding average random consistency index RI was found from Table 2, and the uniformity ratio $\mathrm{CR}=\mathrm{CI} / \mathrm{RI}$ was obtained as $\mathrm{CR}=0.003$ and $\mathrm{CR}<0.01$, which, the judgment matrix of first-level indicators had satisfactory consistency, indicating that the weights were reasonably set.

Table 2. Evaluation random consistency indicator RI

\begin{tabular}{|l|l|l|l|l|l|l|l|l|c|}
\hline \multicolumn{1}{|c|}{ Dimension } & $\mathbf{1}$ & $\mathbf{2}$ & $\mathbf{3}$ & $\mathbf{4}$ & $\mathbf{5}$ & $\mathbf{6}$ & $\mathbf{7}$ & $\mathbf{8}$ & $\mathbf{9}$ \\
\hline RI & 0 & 0 & 0.58 & 0.96 & 1.12 & 1.24 & 1.32 & 1.41 & 1.45 \\
\hline
\end{tabular}

Based on third-level indicators, the weight of each term was set as wi, the evaluation score of each term was gi, where I was the ith dimension of the third-level indicator. The quantitative formula of the eventual evaluation score $(G)$ was as follows:

$$
G=\sum_{i=1}^{n}\left(w_{i} g_{i}\right)
$$

Where $\mathrm{n}=26$,

Combining with the evaluation indicator system, the specific formula of the evaluation score of students' learning effect was:

$$
G=\sum_{i=1}^{n}\left(w_{i} g_{i}\right)
$$


Since the evaluation methods of each indicator included systematic evaluation, teacher evaluation and student mutual evaluation, the score of a specific indicator, therefore, was gi $=($ System evaluation $\mathrm{g} 1+$ teacher evaluation $\mathrm{g} 2+$ student evaluation g3) i.

By using all the results of single sorting in the same hierarchy, the weights of the factor importance in this hierarchy corresponding to previous hierarchy could be calculated, which was the total sorting of this hierarchy. The total hierarchy sorting needed to be done from top to bottom and one by one. Let the order of $\mathrm{n}$ elements on the $\mathrm{k}-1$ hierarchy to the total target be calculated as

$$
w^{(k-1)}=\left(w_{1}^{(k-1)}, \cdots, w_{n}^{(k-1)}\right)^{T}
$$

For $n_{k}$ elements at hierarchy $\mathrm{K}$, the single-sorted vector with the jth element as criterion at hierarchy K-1 was calculated as

$$
u_{j}^{(k)}=\left(u_{1 j}^{(k)}, u_{2 j}^{(k)}, \cdots, u_{n_{k} j}^{(k)}\right), j=1,2, \cdots n \cdot k=1,2, \cdots, n_{k}
$$

Where the weights not determined by the jth elements were set to zero, then an $n_{k} \times n$ order matrix was obtained as

$$
u_{j}^{(k)}=\left(u_{1 j}^{(k)}, u_{2 j}^{(k)}, \cdots, u_{n_{k} j}^{(k)}\right)=\left(\begin{array}{cccc}
u_{11}^{(k)} & u_{12}^{(k)} & \cdots & u_{1 n}^{(k)} \\
u_{11}^{(k)} & u_{12}^{(k)} & \cdots & u_{1 n}^{(k)} \\
\vdots & \vdots & \vdots & \vdots \\
u_{n_{k} 1}^{(k)} & u_{n_{k} 2}^{(k)} & \cdots & u_{n_{k} n}^{(k)}
\end{array}\right)
$$

Where the jth column of $U^{(k)}$ was the single sorted vector of $n_{k}$ elements in the kth hierarchy to the jth element in the k-1 hierarchy.

$$
w^{(k)}=\left(w_{1}^{(k)}, \cdots, w_{n}^{(k)}\right)^{T}
$$

Then

$$
w^{(k)}=U^{(k)} w^{(k-1)}=\left(\begin{array}{cccc}
u_{11}^{(k)} & u_{12}^{(k)} & \cdots & u_{1 n}^{(k)} \\
u_{11}^{(k)} & u_{12}^{(k)} & \cdots & u_{1 n}^{(k)} \\
\vdots & \vdots & \vdots & \vdots \\
u_{n_{k} 1}^{(k)} & u_{n_{k}}^{(k)} & \cdots & u_{n_{k} n}^{(k)}
\end{array}\right)\left(\begin{array}{l}
w_{1}^{(k-1)} \\
w_{2}^{(k-1)} \\
\vdots \\
w_{n}^{(k-1)}
\end{array}\right)=\left(\begin{array}{l}
\sum_{j=1}^{n} u_{1 j}^{(k)} w_{j}^{(k-1)} \\
\sum_{j=1}^{n} u_{2 j}^{(k)} w_{j}^{(k-1)} \\
\vdots \\
\sum_{j=1}^{n} u_{n_{k} j}^{(k)} w_{j}^{(k-1)}
\end{array}\right)
$$

And

$$
w_{i}^{(k)}=\sum_{j=1}^{n} u_{i j}^{(k)} w_{j}^{(k-1)}, i=1,2, \cdots, n_{k}
$$

The calculation of judgment matrix and weight of second-level indicators and thirdlevel indicators under first-level indicators were the same as that of first-level indicators, and the final weight calculation results were shown in Table 3. 
Paper-Deep Learning Technology Based on Intelligent Teaching in Social Psychology Courses

Table 3. Indicators of intelligent classroom teaching evaluation system based on deep learning

\begin{tabular}{|c|c|c|c|}
\hline First-level indicator & Second-level indicator & $\begin{array}{l}\text { Third-level } \\
\text { indicator }\end{array}$ & $\begin{array}{c}\text { Fourth-level in- } \\
\text { dicator }\end{array}$ \\
\hline $\begin{array}{l}\text { Knowledge level } \\
(0.23)\end{array}$ & $\begin{array}{c}\text { Knowledge acquirement } \\
(0.051) \\
\text { Knowledge maintenance } \\
(0.067) \\
\text { Knowledge migration } \\
(0.112)\end{array}$ & $\begin{array}{l}\text { Knowledge acquisition }(0.014) \\
\text { Skill improvement }(0.037) \\
\text { Performance }(0.035) \\
\text { Knowledge forgetting rate }(0.032) \\
\text { Assimilative migration }(0.031) \\
\text { Compliant migration }(0.035) \\
\text { Recombination migration }(0.046)\end{array}$ & Ellipsis \\
\hline $\begin{array}{l}\text { Process level } \\
(0.65)\end{array}$ & $\begin{array}{c}\text { Learning preparation } \\
(0.091) \\
\text { Learning participation } \\
(0.312) \\
\text { Self-reflection } \\
(0.247)\end{array}$ & \begin{tabular}{|c|} 
Knowledge preparation $(0.034)$ \\
Skill preparation $(0.046)$ \\
Emotion preparation $(0.011)$ \\
Information exchange $(0.053)$ \\
Problem mastery $(0.065)$ \\
Problem solving $(0.112)$ \\
Practical innovation $(0.082)$ \\
Intervention adjustment $(0.183)$ \\
Deep processing of knowledge $(0.064)$
\end{tabular} & Ellipsis \\
\hline Emotion level (0.12) & $\begin{array}{c}\text { Learning attitude } \\
(0.055) \\
\text { Learning will }(0.031) \\
\text { Learning willingness } \\
\quad(0.034)\end{array}$ & $\begin{array}{c}\text { Learning adaptation }(0.014) \\
\text { Interest in learning }(0.017) \\
\text { Learning motivation }(0.024) \\
\text { Self-awareness }(0.008) \\
\text { Decisiveness }(0.007) \\
\text { Self-control }(0.007) \\
\text { Persistence }(0.009) \\
\text { Values }(0.011) \\
\text { Satisfaction level }(0.015) \\
\text { Identity }(0.008)\end{array}$ & Ellipsis \\
\hline
\end{tabular}

\subsection{The application of problem-discussion collaborative teaching in social psychology}

The application of problem-discussion collaborative teaching in social psychology has changed the traditional mode of "Teachers teaching, students listening", improving the interaction between teachers and students, letting students become the main body who proactively explore and have team collaboration. Students' interest in learning was stimulated, resulting in a better teaching quality. A new teaching mode orienting at problems solving and team collaboration was thus formed to improve the students' ability in problem solving, information acquisition and team collaboration, thus the teaching objectives were integrated.

Figure 3 has shown the scene of teachers and students learning together using collaborative method when our team was carrying out the teaching of social psychology. It could be seen that the objectives were not only to let students acquire professional knowledge, more importantly, to train their self-thinking ability to solve problems. Double qualified teacher teaching mode can integrate multiple teaching objectives and improve students' comprehensive ability. Teaching was organized by means of problem-centered form to cultivate students' practical ability in solving problems; The 
teaching was carried out in groups to cultivate students' team working in the cooperation. Figure 4 showed teachers applying psychological software in the intelligent teaching to conduct heuristic teaching for students.

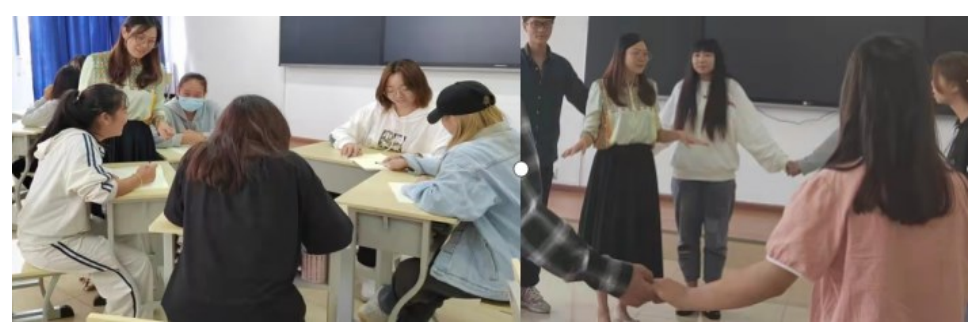

Fig. 3. The application of problem-discussion collaborative teaching in social psychology

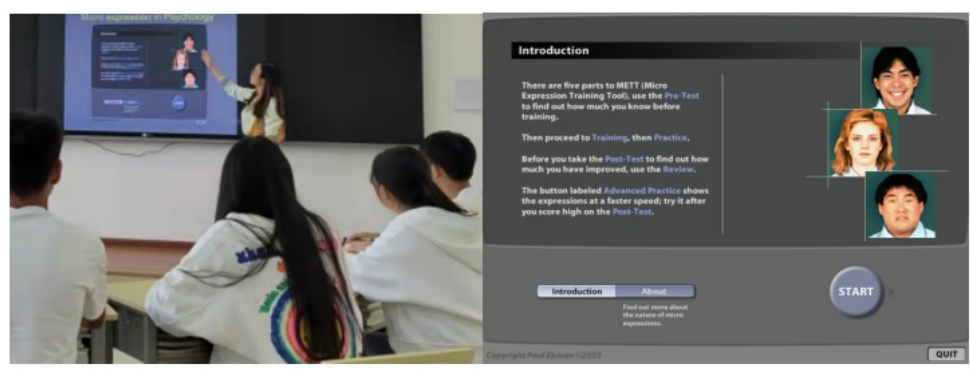

Fig. 4. Application of psychology software in intelligent teaching platform

It could be seen from Figure 4 that intelligent teaching consisted of intelligent preview, intelligent class, intelligent promotion and intelligent evaluation, which aimed at promoting deep learning in social psychology. The whole teaching process was carried out under the support of teaching environment, teaching resources and technical strategy. This mode has provided an integrated learning environment and teaching resources. Firstly, real teaching environment and virtual teaching environment were mixed. Secondly, double qualified teachers were the basis for the mode. Thirdly, the resources were freely combined into teaching resources suitable for the courses according their different characteristics. Relying on big data technology in intelligent classroom, students' learning behaviors had habits were analyzed to help teachers carry out teaching according to students' aptitude. Through independent preview, design and creation activities, students could achieve advanced learning from imitation to innovation. The various stages of social psychology were closely combined to enable students to gradually internalize the knowledge they have learned, thus achieving a higher level of deep learning. The paper has carried out an in-depth analysis of learner characteristics, characteristics of social psychology and teaching situation of social psychology. Based on the theory of deep learning and taking teaching environment, teaching resources and technical strategy into comprehensive consideration and intelligence as the core idea, the study has designed an intelligent teaching mode that integrated the " $3+1$ " teaching mode of social psychology, which was intelligent preview, intelligent class, intelligent 
promotion and intelligent evaluation. The specific structure of the mode was shown in Figure 5.

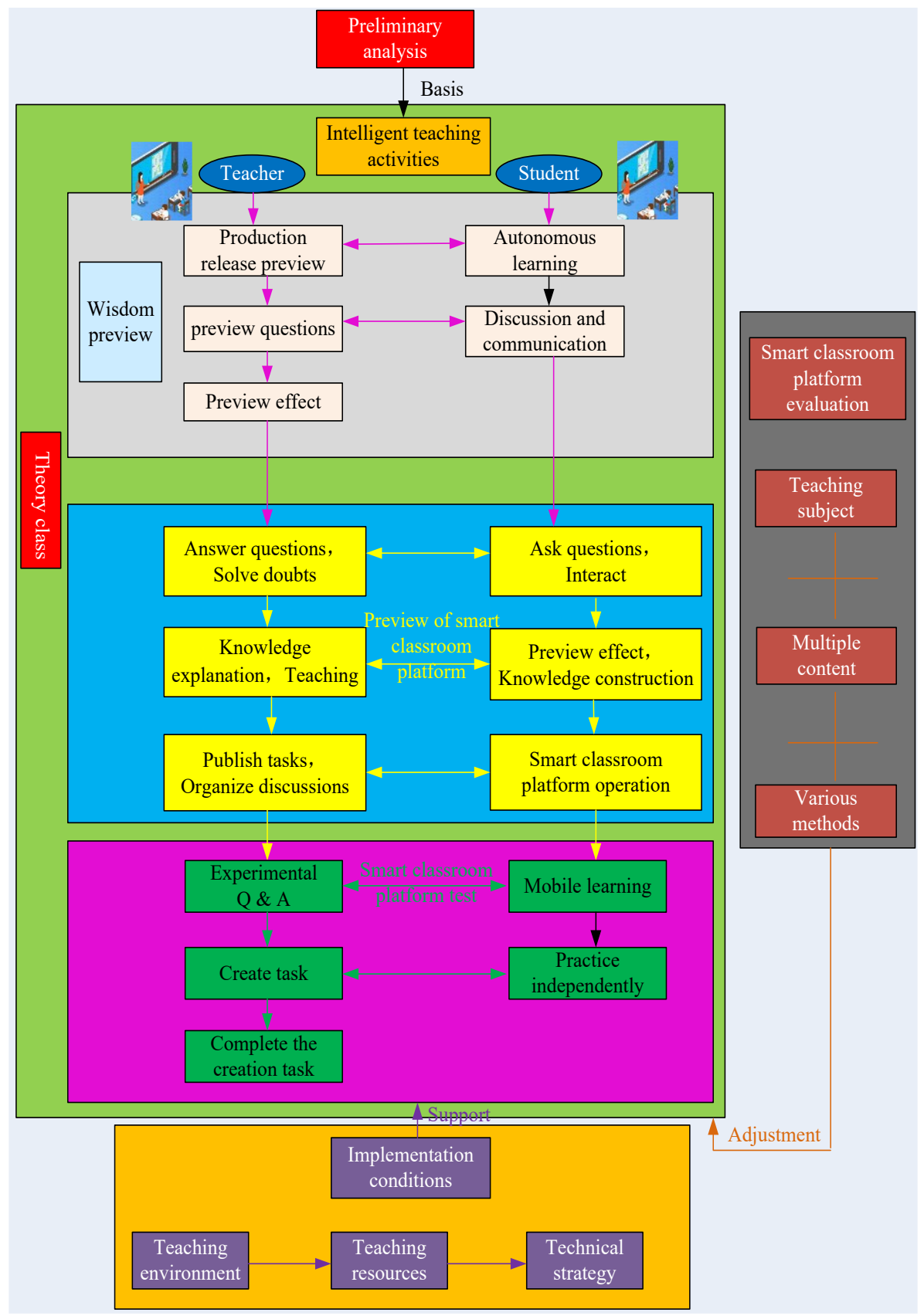

Fig. 5. Structure of the teaching mode of social psychology intelligent classroom 


\section{Teaching example and effect}

\subsection{Teaching example}

The steps of the establishment of intelligent teaching process were interlocked. Intelligent preview was the basis of intelligent class, and intelligent class was the preparation of intelligent promotion. The feedback of preview was one of the sources of intelligent Q \& A in intelligent class, and the effect of preview was the basis for the determination of difficult knowledge in intelligent class. The tasks issued by intelligent creation and design in intelligent class provided scheme for the completion of practice. The intelligent class has effectively combined on-line interaction and off-line interpretation, providing a mixed intelligent environment. Based on teachers' interpretation, Yuketang was used for the interaction. Through the 'bullet comment' function in Yuketang, teachers paid attention to students' feedback, and could organize a discussion on most frequently raised questions. For individual question, teachers could answer to students face to face. This combination mode can better give play to students' subjective initiative, improving the emotional connection between teachers and students, students and students, not only saving time, but also improving the teaching quality.

Intelligent class used Internet technologies to divided the teaching process into three steps: intelligent Q \& A, intelligent interpretation and intelligent creation, as shown in Figure 6. Each step has activities of teachers and students:

1. Intelligent Q \& A referred to teachers answering questions came from the judgment of the preview stage and also from the students.

2. Intelligent interpretation meant that teachers determining key and difficult contents to be interpreted according to students' preview, or displaying practice according to the needs of the course. Knowledge was constructed and interaction was generated between teachers and students.

3. Intelligent creation meant teachers issuing creative tasks to students who were divided into groups to design schemes and evaluate on each other.

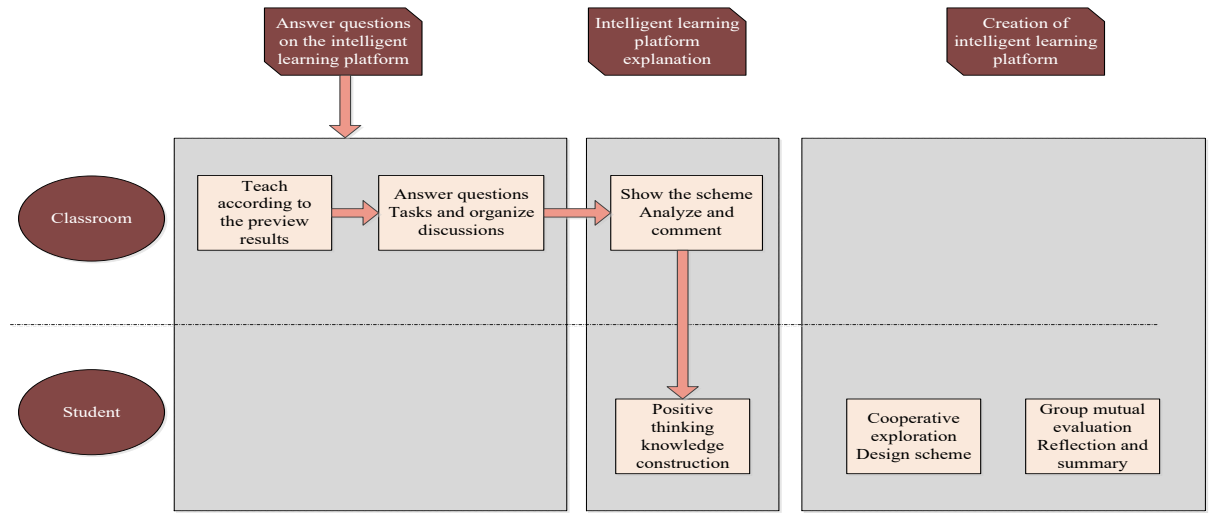

Fig. 6. Teaching process of intelligent classroom based on deep learning 
It could be seen from Figure 7 that intelligent classrooms based on information technology made teaching more efficient, intelligent and humane. Not only teachers could use more abundant forms of demonstration to improve teaching contents and promote the interaction, but also students could flexibly and independently discuss on questions in class and rapidly acquire learning resources. In the collaborative intelligent classroom, each group had its own module. Students could comprehensively express their ideas in the group and also share their ideas to other groups through screen sharing, which not only satisfied students' willingness to express, but also promote and stimulate the atmosphere of the class.

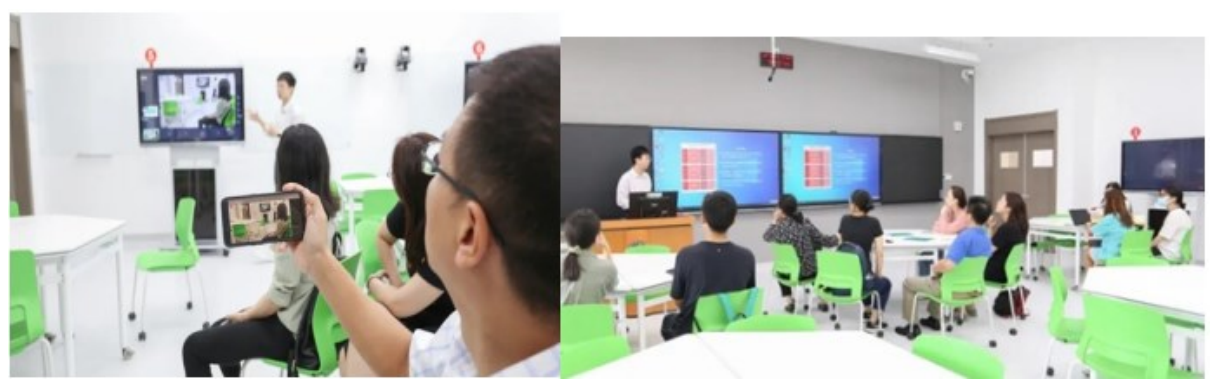

Fig. 7. Classroom demonstration of deep learning through intelligent classroom

\subsection{Teaching effect}

A pre-experiment was carried out, in which research objects were selected strictly in accordance with the inclusion and exclusion criteria. A total of 94 students majored in social psychology from grade 2020 were selected for the pre-experiment. Two of the teaching subjects were selected to carry out the teaching evaluation system of intelligent classroom based on deep learning. After the lectures of the pre-experiment were completed, the Scale of Self-learning Ability of Students Majored in Social Psychology was distributed, filled on site and all collected. After data was input, reliability analysis was conducted, and the Cronbach's $\alpha$ coefficient of the scale was 0.812 , showing good reliability and validity.

Based on the research purpose and characteristics of research objectives, literature review and consulting experts for repeated argumentation, an integrated teaching program was designed. Through the use of cluster sampling, members of the experimental group and the control group might communicate on the teaching content in the teaching process. To avoid mutual influence between the experimental group and the control group, the significance and purpose of this study were told to the subjects to reduce interference factors.

The study has carried out an experiment on 94 students from grade 2020 of a university who studied social psychology courses. Groups were divided according to class. 47 students in Class 1 were categorized as the experimental group, in which teaching evaluation system of intelligent classroom based on deep learning was used; 47 students in Class 2 were categorized as the control group, in which traditional teaching mode 
was used. The two groups of students had no obvious difference in performance before the experiment, thus they were comparable.

The comparison of test results of two groups (See table 2). It could be seen from table 4 that the results of the experimental group were higher than those of the control group, thus the difference had statistical significance $(\mathrm{P}<0.05)$.

Table 4. Comparison of test scores between the experimental group and the control group

$$
(\bar{x} \pm s \text {, point })
$$

\begin{tabular}{|l|c|c|c|c|c|}
\hline \multicolumn{1}{|c|}{ Group } & Average score & Final score & t & P & Total score \\
\hline Experimental group $(\mathrm{n}=47)$ & $26.1 \pm 4.8 \#$ & $63.2 \pm 3.9 \#$ & -2.228 & 0.024 & $89.3 \pm 8.7 \#$ \\
\hline Control group $(\mathrm{n}=47)$ & $22.4 \pm 3.1 \#$ & $58.6 \pm 2.2 \#$ & -2.302 & 0.028 & $81.0 \pm 5.3 \#$ \\
\hline
\end{tabular}

Note: Compared with the control group, \#P $<0.05$.

The comparison of learning enthusiasm between the two groups (see Table 5). In terms of the number of raised questions, the number of discussions and speeches, the number of references and time of self-study, the experimental group had higher learning enthusiasm than the control group, and the difference had statistical significance $(\mathrm{P}<$ $0.05)$.

Table 5. Comparison of learning ability between the experimental group and control group

\begin{tabular}{|l|c|c|c|c|}
\hline \multicolumn{1}{|c|}{ Item } & Before teaching $(\mathbf{n}=\mathbf{4 7})$ & After teaching $(\mathbf{n}=\mathbf{4 7})$ & $\mathbf{t}$ & $\mathbf{P}$ \\
\hline Learning motivation & $32.91 \pm 3.68$ & $34.55 \pm 4.16$ & -2.022 & 0.046 \\
\hline Self-management & $28.98 \pm 3.58$ & $30.38 \pm 4.04$ & -1.782 & 0.039 \\
\hline Collaboration & $16.62 \pm 1.74$ & $18.85 \pm 2.22$ & -5.437 & $<0.001$ \\
\hline Information literacy & $18.85 \pm 1.96$ & $20.51 \pm 2.62$ & -3.480 & 0.001 \\
\hline Total score & $97.36 \pm 9.06$ & $104.30 \pm 10.50$ & -3.429 & 0.001 \\
\hline
\end{tabular}

Note: Compared with the control group, $\mathrm{P}<0.05$.

The results have shown that the teaching evaluation system of intelligent classroom based on deep learning can significantly improve the final and total score of the test of social psychology, fully promote the enthusiasm of students, increase the number of raised questions, which are better than traditional teaching mode in students' independent learning and personal development, communication skills, knowledge of social psychology, analysis and problem-solving skills. By analyzing the reasons, it can be concluded that firstly, the teaching mode has introduced cooperative learning into social psychology, promoting the balanced development of students' academic goals and cooperative goals. Based on collaborative learning, the atmosphere in psychology class can be effectively improved, members of the group are encouraged to actively participate in the activities, competition awareness is raised between groups, avoiding the phenomenon that only part of the students are active and others are negative. Meanwhile, intelligent based on deep learning can scientifically satisfy students' cognition and needs, enhancing cooperative consciousness inside the group, turning passive receipt of knowledge to proactively participation, so that non-cognitive qualities can be formed, students' interest in learning can be cultivated and their abilities in social communication can be improved. 


\section{Conclusions}

The study has designed and applied intelligent classroom based on teaching techniques with deep learning. Firstly, an intelligent teaching mode of social psychology was designed. With the help of intelligent teaching tools and combined with problemdiscussion collaborate teaching method, the essence and effect evaluation pattern were demonstrated in a complete teaching process. Moreover, it was applied in the practice of Social Psychology courses and the results have shown certain improvements in the teaching mode. The conclusions of the study are as follows:

- The intelligent teaching mode can scientifically integrate theory and practice, providing students an integrated learning environment of online and offline study. It also provides an excellent platform for teachers in online teaching, as well as provides an environment for students to have fragmented study anywhere at any time.

- Teaching based on deep learning can help teachers know the characteristics of learners and courses, and teaching situation in advance, and it is beneficial to form scientific teaching environment, teaching resources and skills. This mode can satisfy the needs of multiple communication and interaction, as well as scientific and efficient completion of teaching objectives.

- Taking the analysis of learning objectives of accurate teaching, the study has established a three-level evaluation system based on knowledge level, process level and emotion level, which scientifically reflects the learning effect of students in accurate teaching activities and effectively promote students' self-study.

- Problem-discussion collaborative learning is one of the communication ways between teachers and students, and between students. Problem-centered teaching and group collaboration can effectively stimulate students enthusiasm in study.

\section{References}

[1] Chen, X., Niu, C.J., Zheng, H.Y. Construction of flipped classroom teaching model of social psychology. Journal of HeBei United University (Health Sciences), 2016, vol. 18(2), pp. 142-144.

[2] Jin, C.C. Application of situational participatory teaching method in the teaching of "social psychology". Forestry Education in China, 2019, vol. 37(2), pp. 50-53.

[3] Jian, W., He, J., Kai, C., et al. Collaborative Filtering and Deep Learning Based Recommendation System For Cold Start Items. Expert Systems with Applications, 2016, vol. 69, pp. 29-39. https://doi.org/10.1016/j.eswa.2016.09.040

[4] Innes, J.M., \& Chambers, T.P. The evaluation of significant figures in the history of social psychology: A class exercise in the teaching of introductory social psychology. 2017, vol. 16(1), pp. 105-114. https://doi.org/10.1177/1475725716680698

[5] Koca-Atabey, M. Revisiting the Stanford Prison Experiment from the Perspective of the Social Model of Disability: A Teaching Experience. Education as Change, 2020, vol. 24, pp. 5715. https://doi.org/10.25159/1947-9417/5715

[6] Bramesfeld, K.D., \& Good, A. C'est la vie! the game of social life using an intersectionality approach to teach about privilege and structural inequality. Teaching of Psychology, 2016, vol. 43(4), pp. 294-304. https://doi.org/10.1177/0098628316662758 
Paper-Deep Learning Technology Based on Intelligent Teaching in Social Psychology Courses

[7] Stroet, K., Opdenakker, M.C., \& Minnaert, A. Need supportive teaching in practice: a narrative analysis in schools with contrasting educational approaches. Social Psychology of Education, 2015, vol. 18(3), pp. 585-613. https://doi.org/10.1007/s11218-015-9290-1

[8] Li, X. Individual psychological characteristics of new social media and foreign language teaching design - from the perspective of social psychology. China University Teaching, 2016, vol. 37(4), pp. 44-48.

[9] Pei, T.J., Zhang, Y.Y., Wu, M. Application of case teaching and scene simulation teaching in nursing psychology teaching. Psychological Doctor, 2017, vol. 23(30), pp. 321-322.

[10] Kou, Y., Fu, X.Y., Yuan, M.L., et al. Teaching reform of social psychology based on students' needs and learning rules. Educational Research and Experiment, 2016, vol. 28(1), pp. 87-90.

[11] Bergdahl, N., Nouri, J., Karunaratne, T., et al. Learning Analytics for Blended Learning: A Systematic Review of Theory, Methodology, and Ethical Considerations. International journal of learning analytics and artificial intelligence for education, 2020, vol. 2(2), pp. 46-79. https://doi.org/10.3991/ijai.v2i2.17887

[12] Zhang, H., Cui, Y.L., Yu, L.Y., et al. Study of Classroom Event Logic Graph of Intelligent Teaching based on Method of Data Mining. Journal of Distance Education, 2020, vol. 38(2), pp. $80-88$.

[13] Jian, X.H., Xiao, Z.Q., Gong, Q.A., et al. Research and Design of Smart Classroom System Based on Internet of Things Technology and Smart Classroom. Logistics Engineering and Management, 2018, vol. 40(12), pp. 176-178.

[14] Su, H.Y. A Research-Based Smart Classroom in An Exercise Physiology Course. International Journal of Emerging Technologies in Learning, 2021, vol. 16(18), pp. 97-112. https://doi.org/10.3991/ijet.v16i18.25339

[15] Saraubon, K. Learning Media Repository and Delivery System for Smart Classroom using IoT and Mobile Technologies. International Journal of Interactive Mobile Technologies, 2019, vol. 13(2), pp. 66-77. https://doi.org/10.3991/ijim.v13i02.9941

[16] Wang, T., Fan, L.X., Han, N. Application of Froggipedia app in middle school biology classroom. Primary and Middle School Educational Technology, 2018, vol. 466(10), pp. 79-80.

\section{$7 \quad$ Author}

Dan Li is a Lecturer in the Yunnan Vocational Institute of Energy Technology, Qujing, Yunnan, China.

Article submitted 2021-10-03. Resubmitted 2021-11-10. Final acceptance 2021-11-11. Final version published as submitted by the author. 